Conclusion: Similar to observations in DMARD-naive patients with PsA, patients who were biologic naive but may have had experience with a maximum of 1 csDMARD, including those with enthesitis, and who were in ModDA at baseline had a higher probability of achieving treatment targets (cDAPSA REM or LDA) at Week 52 with continued APR treatment compared with those with HDA Acknowledgements: This study was funded by Celgene. Additional analyses were funded by Amgen Inc. Writing support was funded by Amgen Inc. and provided by Kristin Carlin, RPh, MBA, of Peloton Advantage, LLC, an OPEN Health company.

Disclosure of Interests: Peter Nash Consultant of: AbbVie, BMS, Celgene, Gilead/Galapagos, GSK, Janssen, Lilly, MSD, Novartis, Pfizer, and Samsung, Grant/research support from: AbbVie, BMS, Celgene, Gilead/Galapagos, GSK Janssen, Lilly, MSD, Novartis, Pfizer, and Samsung, Sven Richter Employee of: Amgen Inc., Shauna Jardon Employee of: Amgen Inc., Lichen Teng Employee of: Amgen Inc., Jessica A. Walsh Consultant of: AbbVie, Amgen Inc., Janssen, Lilly, Merck, Novartis, Pfizer, and UCB, Grant/research support from: AbbVie, Amgen Inc., Janssen, Lilly, Merck, Novartis, Pfizer, and UCB.

DOI: 10.1136/annrheumdis-2021-eular.2198

\section{AB0553 $\quad$ BASELINE DISEASE ACTIVITY AS A PREDICTOR FOR ACHIEVING CDAPSA TREATMENT TARGETS WITH APREMILAST IN DMARD-NAIVE PATIENTS WITH MANIFESTATIONS OF ACTIVE PSORIATIC ARTHRITIS}

P. J. Mease ${ }^{1}$, A. Kavanaugh ${ }^{2}$, A. Ogdie ${ }^{3}$, A. F. Wells ${ }^{4}$, M. Bergman ${ }^{5}$, D. D. Gladman ${ }^{6}$, F. Behrens ${ }^{7}$, Y. Klyachkin ${ }^{8}$, S. Richter ${ }^{8}$, L. Teng ${ }^{8}$, J. S. Smolen ${ }^{9}$. ${ }^{1}$ Swedish Medical Center/Providence St. Joseph Health and University of Washington School of Medicine, Department of Rheumatology, Seattle, United States of America; ${ }^{2}$ University of California, San Diego, School of Medicine, Division of Rheumatology, Allergy, and Immunology, La Jolla, United States of America: ${ }^{3}$ University of Pennsylvania, Department of Rheumatology, Philadelphia, United States of America; ${ }^{4}$ Aurora Rheumatology and Immunotherapy Center, Department of Rheumatology, Franklin, United States of America; ${ }^{5}$ Drexel University College of Medicine, Division of Rheumatology, Philadelphia, United States of America; ${ }^{6}$ Schroeder Arthritis Institute, Rheumatology, Toronto, Canada; ${ }^{7}$ Rheumatology and Fraunhofer ITMP - Translational Medicine and Pharmacology, Goethe University, Department of Rheumatology, Frankfurt, Germany; ${ }^{8}$ Amgen Inc., Global Medical Affairs, Thousand Oaks, United States of America; ${ }^{9}$ Medical University of Vienna, Department of Rheumatology, Vienna, Austria

Background: In PALACE 4, DMARD-naive patients (pts) with moderately active (ModDA) psoriatic arthritis ( $P S A$ ) at baseline (BL) were more likely to achieve Clinical Disease Activity Index for PsA (cDAPSA) treatment targets (cDAPSA remission [REM] or low disease activity [LDA]) at Week 52 with continued apremilast $30 \mathrm{mg}$ BID (APR) treatment than pts with high disease activity (HDA) at BL. Pts who achieved cDAPSA treatment targets also had no or mild articular and extra-articular disease activity by Week 52 . Whether specific PsA manifestations other than arthritis impact the achievement of cDAPSA treatment targets in this population is unknown.

Objectives: To assess the predictive value of $B L$ clinical disease status on achieving cDAPSA treatment targets in DMARD-naive pts in PALACE 4 with PsA in ModDA or HDA who exhibited manifestations of skin involvement, enthesitis, and/or dactylitis at BL.

Methods: This post hoc analysis included APR-treated pts in ModDA or HDA with available cDAPSA data at $\mathrm{BL}$ and Week 52 who exhibited any of the PsA manifestations at $B L$, including skin-involved body surface area $(B S A) \geq 3 \%$, Maastricht Ankylosing Spondylitis Entheses Score (MASES) $>0$, or dactylitis count $>0$. Pts were divided into 4 subgroups based on number of manifestations: $\geq 1$, only 1 , any 2 , or all 3 . The proportions of pts who shifted across ModDA ( $>13$ to $\leq 27$ ) and HDA (>27) cDAPSA categories at BL to REM ( $\leq 4)$ and LDA (>4 to $\leq 13$ ) treatment targets at Week 52 were calculated (data as observed).

Results: In 176 PALACE 4 pts with PsA receiving APR, 165 had involvement in $\geq 1$ PsA manifestation in addition to peripheral arthritis (ie, skin/enthesitis/dactylitis) at $\mathrm{BL}$. This population had a mean age of 48.8 years, PsA duration of 3.6 years, Psoriasis Area and Severity Index (PASI) score of 6.6, MASES of 3.8, and dactylitis count of 3.5 (Table 1). Within this subgroup, $32.7 \%$ had only 1 of these non-arthritic PsA manifestations, $50.9 \%$ had any 2 , and $16.4 \%$ had all 3 . In pts with $\geq 1$ manifestation, a greater proportion in ModDA achieved REM/LDA at Week 52 than those in HDA ( $66.7 \%$ vs $32.2 \%$; risk difference: 0.34 ) (Figure 1 ). Similarly, greater rates of treatment target achievement were observed in subgroups of pts in ModDA vs HDA and only 1 (72.2\% vs $39.1 \%$; risk difference: 0.33 ), any 2 ( $57.1 \%$ vs $28.6 \%$; risk difference: 0.29 ), or all 3 (75.0\% vs $33.3 \%$; risk difference: 0.42 ) PsA manifestations (Figure 1).

Conclusion: In DMARD-naive pts exhibiting various non-arthritic manifestations of active PSA (ie, skin/enthesitis/dactylitis), those in ModDA at BL were more likely to achieve cDAPSA REM or LDA at Week 52 of APR treatment than pts in HDA. This observation was consistent whether pts had only 1 or multiple manifestations. These findings are consistent with the probability of achieving treatment targets demonstrated in the overall population in PALACE $4(61.7 \%$ ModDA vs $28.2 \%$ HDA).

Table 1. BL Demographics and Disease Characteristics in Pts With $\geq 1$ Manifestations of PsA (Skin Involvement, Enthesitis, and/or Dactylitis) Treated With APR $(\mathrm{N}=165)$

\begin{tabular}{|c|c|}
\hline Age $^{\star}$, years & $48.8(12.5$ \\
\hline Women, n (\%) & $87(52.7)$ \\
\hline $\mathrm{BMI}^{*}, \mathrm{~kg} / \mathrm{m}^{2}$ & $29.9(6.5)$ \\
\hline Duration of $\mathrm{PsA}^{*}$, years & $3.6(5.0)$ \\
\hline Duration of psoriasis*, years & $15.5(13.3)$ \\
\hline CDAPSA $(0-154)^{\star}$ & $39.4(19.7)$ \\
\hline Swollen joint count $(0-66)^{\star}$ & $10.3(7.7)$ \\
\hline Tender joint count $(0-68)^{*}$ & $18.5(12.9)$ \\
\hline Pt's Assessment of Pain (VAS 0-100 mm) ${ }^{\star}$ & $52.8(21.5)$ \\
\hline Pt's Global Assessment (VAS 0-100 mm)* & $53.8(20.1$ \\
\hline Physician's Global Assessment (VAS 0-100 mm)* & $52.2(17.6)$ \\
\hline PASI score $(0-72)^{*, \dagger}$ & $6.6(5.1)$ \\
\hline MASES $(0-13)^{*, \ddagger}$ & $3.8(3.0)$ \\
\hline Dactylitis count $(0-20)^{\star, \S}$ & $3.5(3.3)$ \\
\hline Corticosteroid use, n (\%) & $13(7.9)$ \\
\hline NSAID use, $\mathrm{n}(\%)$ & $126(76.4)$ \\
\hline
\end{tabular}

${ }^{*}$ Mean (SD). ${ }^{\dagger}$ In pts with BSA $\geq 3 \%$ at $B L .{ }^{\ddagger}$ In pts with enthesitis at BL. ${ }^{\S}$ In pts with dactylitis at BL.

Acknowledgements: This study was funded by Celgene. Additional analyses were funded by Amgen Inc. Writing support was funded by Amgen Inc. and provided by Kristin Carlin, RPh, MBA, of Peloton Advantage, LLC, an OPEN Health company.

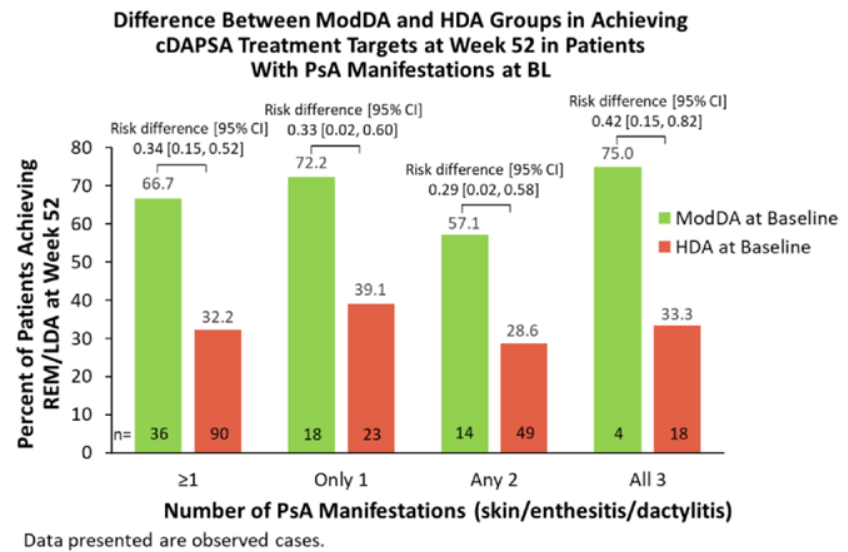

Figure 1.

Disclosure of Interests: Philip J Mease Speakers bureau: AbbVie, Amgen Inc. Eli Lilly, Janssen, Novartis, Pfizer, and UCB, Consultant of: AbbVie, Amgen Inc. Boehringer Ingelheim, BMS, Celgene, Eli Lilly, Galapagos, GSK, Novartis, Pfizer, Sun, and UCB, Grant/research support from: AbbVie, Amgen Inc., Boehringer Ingelheim, BMS, Celgene, Eli Lilly, Galapagos, GSK, Novartis, Pfizer, Sun, and UCB, Arthur Kavanaugh Grant/research support from: AbbVie, Amgen Inc., AstraZeneca, BMS, Celgene, Centocor-Janssen, Pfizer, Roche, and UCB, Alexis Ogdie Consultant of: AbbVie, Amgen Inc., BMS, Celgene, Corrona, Eli Lilly, Gilead Novartis, Pfizer, and UCB, Grant/research support from: Novartis and Pfizer, Alvin F. Wells Speakers bureau: AbbVie, Alexion, Amgen Inc., BMS, Celgene Horizon, Lilly, Novartis, and UCB, Consultant of: AbbVie, Alexion, Amgen Inc. BMS, Celgene, Horizon, Lilly, Novartis, and UCB, Grant/research support from: AbbVie, Celgene, and Lilly, Martin Bergman Shareholder of: Johnson \& Johnson, Speakers bureau: AbbVie, Amgen Inc., Novartis, Pfizer, and Sanofi, Consultant of AbbVie, BMS, Celgene, Genentech, Janssen, Merck, Novartis, Pfizer, and Sanofi, Dafna D Gladman Consultant of: AbbVie, Amgen, BMS, Celgene Corporation, Eli Lilly, Galapagos, Gilead, Janssen, Novartis, Pfizer, and UCB, Grant/research support from: AbbVie, Amgen, BMS, Celgene Corporation, Eli Lilly, Galapagos, Gilead, Janssen, Novartis, Pfizer, and UCB, Frank Behrens Speakers bureau AbbVie, Biotest, Boehringer Ingelheim, Celgene, Chugai, Eli Lilly, Genzyme, Janssen, Novartis, Pfizer, Roche, and UCB, Grant/research support from: AbbVie, Chugai, Janssen, Roche, and Pfizer, Yuri Klyachkin Employee of: Amgen Inc., Sven Richter Employee of: Amgen Inc., Lichen Teng Employee of: Amgen Inc., Josef S. Smolen Speakers bureau: AbbVie, Amgen Inc., AstraZeneca, Astro, Celgene, Celtrion, Eli Lilly, Glaxo, ILTOO, Janssen, Medimmune, MSD, Novartis, Pfizer, Roche, Samsung, Sanofi, and UCB, Consultant of: AbbVie, Amgen Inc. AstraZeneca, Astro, Celgene, Celtrion, Eli Lilly, Glaxo, ILTOO, Janssen, Medimmune, MSD, Novartis, Pfizer, Roche, Samsung, Sanofi, and UCB, Grant/research support from: AbbVie, Eli Lilly, Janssen, MSD, Medimmune, Pfizer, and Roche. DOI: 10.1136/annrheumdis-2021-eular.2224 